\title{
Will Dutch become Flemish? Autonomous developments in Belgian Dutch
}

\author{
HANS VAN DE VELDE, MIKHAIL KISSINE, EVIE TOPS, \\ SANDER VAN DER HARST and ROELAND VAN HOUT
}

\begin{abstract}
In this paper a series of studies of standard Dutch pronunciation in Belgium and the Netherlands is presented. The research is based on two speech corpora: a diachronic corpus of radio speech (1935-1995) and a synchronic corpus of Belgian and Netherlandic standard Dutch from different regions at the turn of the millennium. It is shown that two divergent pronunciation standards have been developing, but it is argued that the divergence will not create two autonomous standard languages. As such, Dutch is not different from its two closest pluricentric neighbors, German and English.
\end{abstract}

Keywords: Dutch, pronunciation, standardization, pluricentic languages, phonological variation and change, real time study

\section{Introduction}

Dutch is an official language in Belgium, the Netherlands, and Surinam, but the variety of Dutch spoken in Surinam is seldom included in studies about variation in Dutch and in discussions on the pluricentric nature of the Dutch language. This paper fits into this tradition and is limited to Dutch spoken in the Low Countries (Belgian and Netherlandic Dutch). ${ }^{1}$ Furthermore, its scope will be limited to phonological variation. The results of a series of studies of standard Dutch will be presented in light of the question as to whether the pronunciation of Belgian Dutch diverges from Netherlandic Dutch and whether it will result in an autonomous Belgian standard, enforcing - or ultimately, even threatening the pluricentric nature of Dutch. All the studies presented in this paper are conducted by the authors and based on a diachronic corpus of radio speech covering a time span of 60 years, and on a synchronic corpus of regional variation in Belgian and Netherlandic standard Dutch at the turn of the millennium. 
In Section 2 we will briefly explain why the official language in Flanders is Dutch and not Flemish. In Section 3 the two speech corpora will be introduced. The phonological variables are presented in Section 4. In Section 5 we will attempt to answer the question of whether Dutch has or will become Flemish in Belgium, an autonomous standard language with its own pronunciation patterns.

\section{Why did Flemish become Dutch?}

Willemyns (2003a) provides an overview of the standardization history of Dutch in the Low Countries and its development as a pluricentric language (Clyne 1992). After the political split of the Dutch language territory in 1585, the standardization process of Dutch was almost completely stopped in Flanders and a codified variety of Dutch developed only in the Netherlands. The Dutch language lost many functions and domains in Flanders, and at the dawn of the Belgian nation (1830), it was no longer equipped to function as an official language. A process of rapid standardization was required, in which two conflicting views coexisted. The so-called particularists advocated their own Flemish standard based on the local regional varieties. The so-called integrationists opted for the northern model and wanted to use the existing standard variety of the Netherlands. The definition of the pronunciation standard was a recurrent theme at the Dutch Congresses on Language and Literature (1849-1912), but they did not result in concrete proposals or a consensus (Willemyns 2003b: 261). A rare $19^{\text {th }}$ century exception was the unified spelling system, which was made compulsory by the Belgian government in 1864, even before it was officially accepted by the Dutch government.

At the beginning of the $20^{\text {th }}$ century it became clear that the integrationists had won the battle, but it should be noted that this discussion was completely irrelevant for the majority of the Flemish population (Willemyns 2003b: 288). The first wave of language planning efforts in the $19^{\text {th }}$ century mainly changed attitudes. The first successful attempts to actually change language behavior date from the 1930s, but their success was still limited due to insufficient contact with language use from the Netherlands. An important impetus was given in the 1960s and 1970s by the popularization of radio and television and the fact that the Flemish media consistently tried to use standard Dutch in both speaking and writing. Furthermore, Flemish radio and television had a prime time program on correct standard language use, and most newspapers had a column to help Flemings gain proficiency in standard Dutch, which were mainly presented and/or written by established professional linguists and university professors (Willemyns 2003a: 110-111). In a few decades, 
Flanders became familiarized with the standard variety of Dutch as it was spoken and written in the Netherlands, despite the absence of governmental backing:

Although there can be no doubt that the integrational policy enjoyed the moral support of almost the entire cultural establishment, there was but very little governmental backing and the main effort was performed through private initiative. There was substantial governmental action on the corpus planning level, though.

(Willemyns 2003: 111)

Only in 1974 was it settled in a decree that the official language of Flanders is Dutch (Geerts 1989). The Belgian government has for a long time been hostile to the language of the majority of its population, and also the relationship with the Kingdom of the Netherlands remained problematic after Belgian independence in 1830. Only after the Second World War did the cultural relations between both countries become more intensive (Aspeslagh et al. 2000: 12). In 1980 Belgium and the Netherlands signed the Treaty of the Dutch Language Union, in which they agreed to pursue a common policy on the Dutch language. ${ }^{2}$

\section{Speech corpora}

This paper is based on analyses of standard Dutch in a diachronic radio corpus (Diachronic Radio Dutch) and in an early $21^{\text {st }}$ century corpus of teachers of Dutch (Variation Teacher Dutch). These two types of speakers are generally considered as competent speakers of the standard language in both the Netherlands and Belgium (Van de Velde \& Houtermans 1999; Smakman 2006).

\subsection{DRD: Diachronic Radio Dutch}

Van de Velde (1996) conducted a real-time study of variation and change in the pronunciation of standard Dutch between 1935 and 1995 (see also Van de Velde, Van Hout \& Gerritsen 1997). ${ }^{3}$ For this reason, professional speakers of the standard language were selected: radio broadcasters. In the Dutch and Belgian radio archives spontaneous speech from broadcasters in two program types was collected: sports commentaries and royal reports. The broadcasters were all males, between 29 and 35 years of age at the moment of recording. As can be seen from Table 1, 
50 broadcasters from the Netherlands, equally distributed over five periods, and 18 from Flanders, equally distributed over three periods, were selected: ${ }^{4}$

Table 1. DRD: the sample of broadcasters, stratified for country, period and programme type $(\mathrm{n}=68)$.

\begin{tabular}{llccccc}
\hline & & 1935 & 1950 & 1965 & 1980 & 1995 \\
\hline The Netherlands & royal reports & 5 & 5 & 5 & 5 & 5 \\
& sports commentaries & 5 & 5 & 5 & 5 & 5 \\
Belgium & royal reports & 3 & & 3 & & 3 \\
& sports commentaries & 3 & & 3 & & 3 \\
\hline
\end{tabular}

\subsection{VTD: Variation Teacher Dutch}

In 1999, a follow-up study on the pronunciation of standard Dutch was started (Van Hout et al. 1999). Another type of professional speakers of the standard language was selected, teachers of Dutch at the secondary school level. ${ }^{5}$ It was argued that these teachers would be representative speakers of the standard language, assuming that these teachers knew they were acting as pronunciation models for younger generations. Furthermore, it was expected that their speech would show more variation than that of broadcasters. Table 2 gives an overview of the research design. Speakers were selected from the Netherlands and from Flanders. Within each country four regions were targeted. Brabant (Flanders-Brabant: F-B) and Randstad (Netherlands Randstad: N-R) are the economic and cultural centers of Flanders and the Netherlands respectively, and the speech of these regions is known to have a strong influence on Belgian and Netherlandic Dutch. We also selected two geographically peripheral areas, which were expected to show clear regional variation. In the Netherlands, these were N-S in the south (Limburg) and N-N in the north (Groningen); in Flanders F-L (Limburg) in the east and F-W (West-Flanders) in the west. N-S and F-E constitute the Limburg dialect area, which crosses the state border. Between the core and the periphery, we also opted for an intermediate zone in the middle of the Netherlands (N-M) and in East-Flanders (F-E). Speakers were not selected from any of the big cities in their respective regions, but from middle-sized provincial towns. Speakers were only included if they had lived in the area they represented before the age of eight and spent at least eight years in the area before the age of 18 . The 160 participants were stratified for sex (male and female) and age (22-40 and 45-60). The subjects were clearly 
instructed about the aim of the research project as a study of standard Dutch pronunciation. The subjects had to perform several tasks during the interview. We will sketch the relevant tasks when we discuss the phonological variables:

Table 2. VTD: the sample of Dutch language teachers, stratified for country, region, sex and age $(\mathrm{n}=160)$.

\begin{tabular}{|c|c|c|c|c|c|}
\hline & & core area & $\begin{array}{l}\text { transition } \\
\text { area }\end{array}$ & $\begin{array}{l}\text { peripheral } \\
\text { area } 1\end{array}$ & $\begin{array}{l}\text { peripheral } \\
\text { area } 2\end{array}$ \\
\hline \multicolumn{2}{|c|}{ The Netherlands } & Randstad & Middle & North & South \\
\hline \multirow[t]{2}{*}{$22-40$} & Male & 5 & 5 & 5 & 5 \\
\hline & Female & 5 & 5 & 5 & 5 \\
\hline \multirow{2}{*}{$45-60$} & Male & 5 & 5 & 5 & 5 \\
\hline & Female & 5 & 5 & 5 & 5 \\
\hline \multirow{2}{*}{\multicolumn{2}{|c|}{ Belgium }} & Brabant & East-Flanders & West-Flanders & Limburg \\
\hline & & & $\mathrm{F}-\mathrm{E}$ & $\mathrm{F}-$ & \\
\hline \multirow[t]{2}{*}{$22-40$} & Male & 5 & 5 & 5 & 5 \\
\hline & Female & 5 & 5 & 5 & 5 \\
\hline \multirow[t]{2}{*}{$45-60$} & Male & 5 & 5 & 5 & 5 \\
\hline & Female & 5 & 5 & 5 & 5 \\
\hline
\end{tabular}

\section{Phonological variables}

In this section we present the results of a number of quantitative studies focusing on the phonological differences between Belgian and Netherlandic Dutch, and on the regional variation patterns within both varieties. We will start in section 4.1 with a multivariate analysis of the general patterns in DRD. In section 4.2 we move to an analysis of loan words in VTD. From section 4.3 onwards data will be drawn from both corpora when discussing vowels (4.3), devoicing of fricatives (4.4), place of articulation of the back fricative (4.5), word final $n$-deletion (4.6) and the pronunciation of $/ \mathrm{r} /(4.7)$. The data in this paper have been published before or will be discussed in detail in forthcoming publications. For statistical analyses and a more detailed interpretation of the results, we refer to these publications. Here we will focus on finding an answer to our central research question concerning the rise of an autonomous standard language in Flanders. Most of the figures are new and adapted for this paper. For the sake of comparison of the DRD with the VTD data, index scores were reversed or variables were defined differently from the original publication. 


\subsection{Phonetic divergence between Netherlandic and Belgian Dutch in DRD}

Eleven phonological variables were analysed to obtain an adequate view of the most important changes in standard Dutch. The majority of these variables will be discussed in more detail in sections 4.3 to 4.7. The index scores of the 11 variables were used as an input for a multidimensional scaling analysis. Van de Velde, Van Hout \& Gerritsen (1997: 378) present the two-dimensional solution as given in Figure 1. The dimension scores obtained for the 68 individual speakers are plotted, split up for period and Belgian vs. Netherlandic Dutch. The horizontal axis, dimension 1, represents change in standard Dutch. The vertical axis, dimension 2, is mainly linked to the place of articulation of $/ \mathrm{r} /$ and word final $n$-deletion (see also section 4.6 and 4.7). As we are interested in change, we will concentrate on the first dimension. The closer the distance between two speakers on the horizontal axis, the more similar their index scores are for the phonological variables indicating change in standard Dutch:

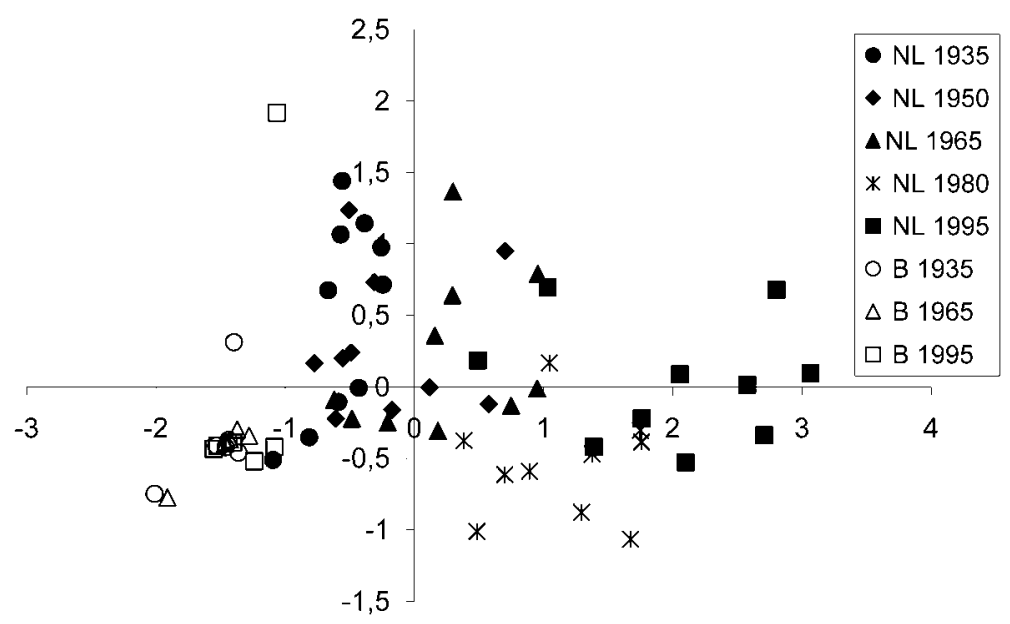

Figure 1. Phonological variation and change in Belgian and Netherlandic Dutch between 1935 and 1995 (DRD). Multidimensional scaling analysis of 11 phonological variables.

Figure 1 reveals a clear pattern of phonological divergence between Belgian and Netherlandic Dutch. Netherlandic Dutch has gradually been changing over time (the more recent the period, the more it turns out to be located to the right of the horizontal axis), while Belgian Dutch has remained stable, showing little variation (to the left of the horizontal axis). Should this pattern be interpreted as an autonomous development of Belgian Dutch? There is no straightforward answer. On the one hand, 
the answer is no, by arguing that a stable pattern is not a development; it is the Netherlandic standard that is moving away from the Belgian standard. On the other hand, the answer is yes, by arguing that no longer following the Netherlandic standard and keeping the original one shows that the Belgian standard has become independent from the (changing) Netherlandic one.

It should be noted that the Dutch and Flemish broadcasting corporations have conducted different language policies, but their language usage has nevertheless continued to reflect the language norms in the respective speech communities. The Dutch broadcasting corporations, which are located in the Randstad area, seem to play a crucial role in the transfer of colloquial Randstad speech characteristics to standard Dutch. The Flemish broadcasting corporation is linguistically much more conservative and tries to block the introduction of colloquial and regional non-standard features into the standard language. In section 2, we already pointed out that the Flemish broadcasting corporation played an important role in the language planning efforts by broadcasting language programmes of a normative and purist nature. Broadcasters had to pass tests to show that they fitted the standard pronunciation model.

\subsection{Loan words VTD}

Loan words are excellent sources to trace patterns of language variation. They may function as markers of between-group differentiation as these words contain sounds in the donor language that are unknown in the host language, implying that they need to be adapted to the phonological system of the host language. Often, there are several options, and sociogeographic factors can play an important role in the linguistic choices. Almost all the words for which Heemskerk \& Zonneveld (2000) - the most recent pronunciation dictionary of Dutch - list a specific Belgian Dutch pronunciation variant are loan words.

The interview with the teachers in VTD contained two word list tasks. Dutch words were presented one by one on a computer screen and the participant was asked to read the words. The word lists contain 318 words, 40 of which are loan words. We will focus on a subset of these loan words and group them into three variables (tie), (nasal) and (a).

- (a): Is the vowel in English loan words pronounced as [e] or [a]? Seven words were selected: plastic, racket, scanner, smash, snack, tandem, and tram.

- (tie): Is the suffix -tie pronounced as [tsi] or [si]? Four words were selected: ambitie 'ambition', frustratie 'frustration', natie 'nation', and politie 'police'. 


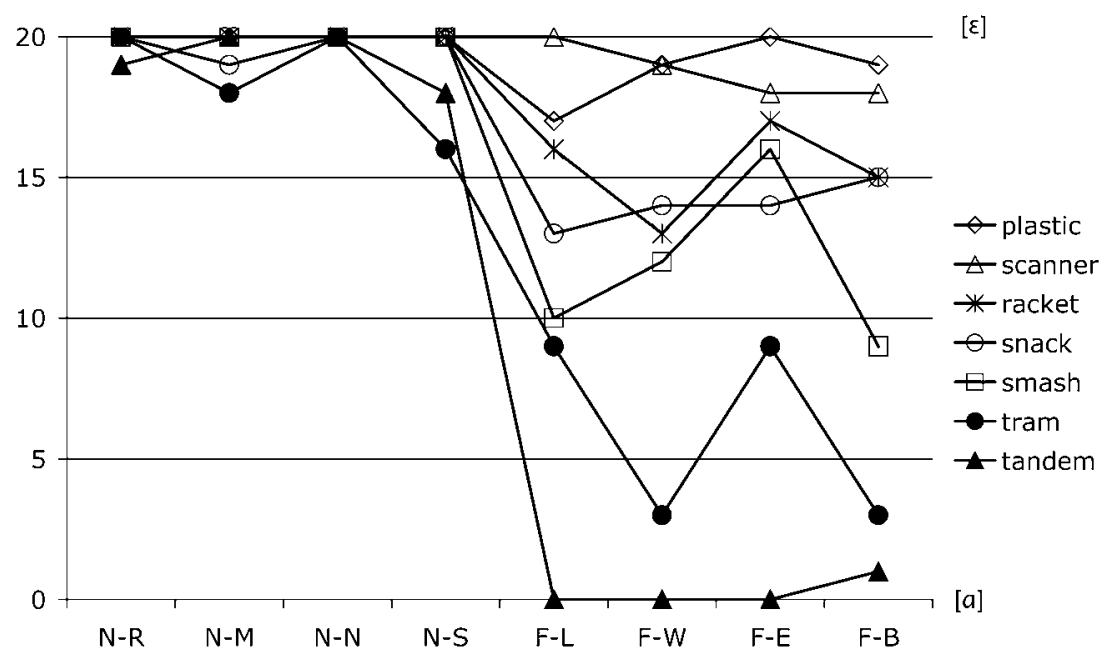

Figure 2. (a): the pronunciation of [ $[\varepsilon]$ versus [a] split up by word and region $(\mathrm{n}=160$, $\mathrm{k}=1120$ ). For each region and word the maximal score is 20 (always [a], never $[\varepsilon])$, the minimal score is 0 (never [a], always $[\varepsilon]$ ).

- (nasal): Is the nasal vowel from the French source nasalized or not? Seven words, containing eight tokens of the variable, were selected: branche 'branch', chanson 'song', croissant 'croissant', enquête 'poll', mannequin 'model', parfum 'perfume', and restaurant 'restaurant'.

A more elaborate presentation and interpretation of the results, including the statistical analyses, can be found in Van de Velde \& Van Hout (2002). Figure 2 presents the results for (a). There are striking differences between Netherlandic and Belgian Dutch. In the Netherlands the picture is very homogeneous with an almost exclusive realization of (a) as $[\varepsilon]$, which is the closest corresponding Dutch vowel to English [æ]. In Flanders, there are large differences between the words, but these differences are fairly consistent over regions. Most words have both pronunciations, with dominant $[\varepsilon]$ in plastic, scanner, racket, and snack. Tram and tandem are most frequently pronounced with the $[\mathrm{a}]$ vowel. The results for (a) suggest that for this variable there are autonomous developments in Belgian Dutch, but due to the lack of a significant age effect, we cannot figure out whether this is a stable variable or language change in progress. ${ }^{6}$

Figure 3 presents the results for (tie). It is obvious that (tie) shows a different pattern from (a) in figure 2 . All regions are very homogeneous, 


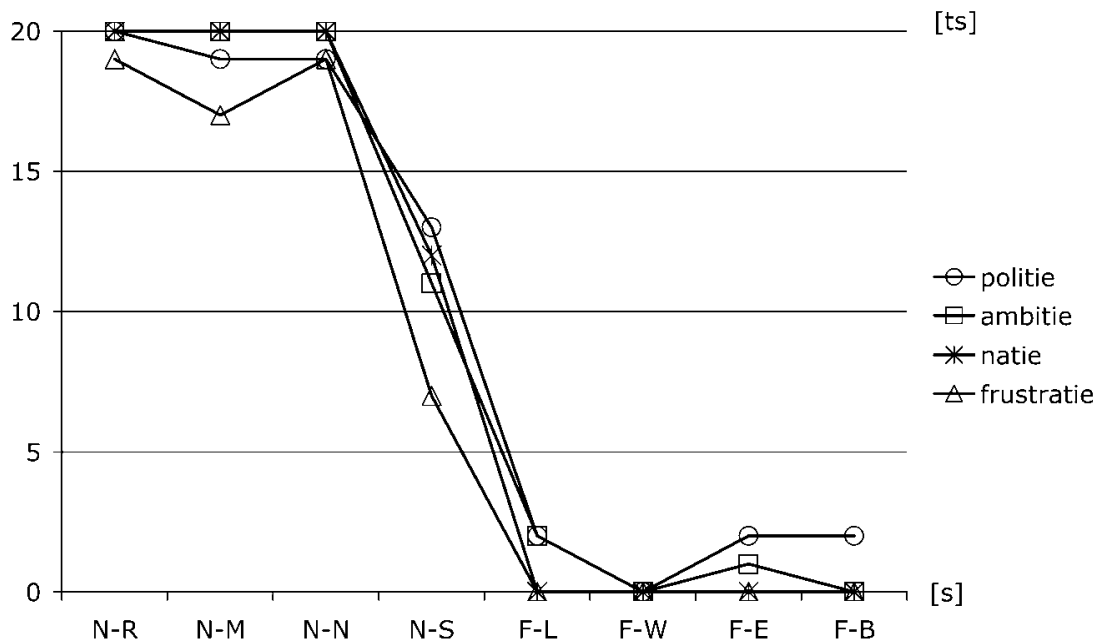

Figure 3. (tie): the pronunciation of [tsi] versus [si], split up by word and region $(\mathrm{n}=160, \mathrm{k}=640)$. For each word and region the maximal score is 20 (always [ts], never [s]), the minimal score is 0 (never [ts], always [s]).

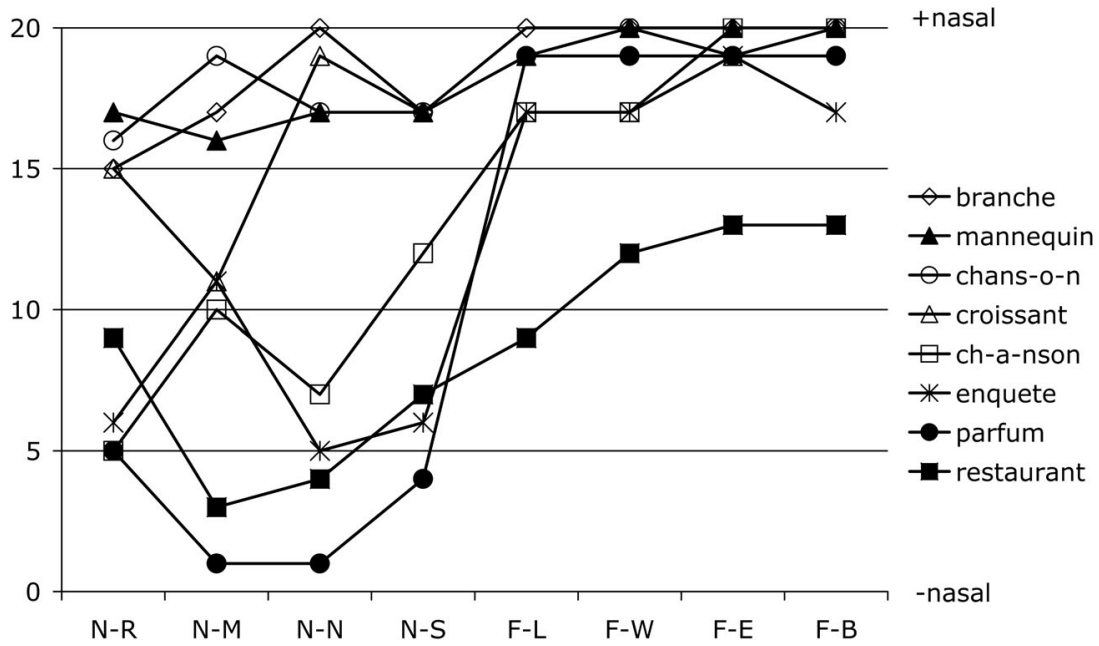

Figure 4. (nasal): the pronunciation of nasal versus oral vowels in seven words, split up by region $(\mathrm{n}=160, \mathrm{k}=1280$ ). For each region the maximal score is 20 (always nasal, never oral), the minimal score is 0 (never nasal, always oral).

showing almost no differences between words, and there is a sharp contrast between the four Belgian regions - almost exclusively [si] pronunci- 
ation - and three of the Netherlandic regions - with almost exclusively [tsi]. N-S (in the South of the Netherlands) has an intermediate position and deviates from the homogeneous [si] pronunciation in the more northern regions in the Netherlands. The results for (tie) support the autonomy of the Belgian standard.

Figure 4 presents the results for (nasal). There are systematic differences between the Netherlands and Belgium, the latter having more nasal vowels (which is the original French pronunciation). Within the countries, however, there are no systematic differences between the regions. In Netherlandic Dutch, there is clear lexical diffusion, with words that are dominantly pronounced with a nasal vowel and others that have a more variable pronunciation. In Belgian Dutch it is mainly the word restaurant that shows variation and does not have the rather homogeneous pronunciation with a nasal vowel that is observed in the other French loan words. The results for (nasal) also support the autonomy of the Belgian standard.

\subsection{Vowel variation}

From the same word list data of VTD, fourteen words were selected that contained a stressed vowel followed by /s/. All Dutch full vowels were represented, except /y/, which does not occur before /s/ in Dutch words. ${ }^{7}$ The words included in this study are aas /as/ 'ace', gas /yas/ 'gas', zes /zes/ 'six', kies /kis/ 'molar', vis /vis/ 'fish', zus /zys/ 'sister', poes /pus/ 'cat', vos /vos/ 'fox', mees /mes/ 'tit', neus /nøs/ 'nose', boos /bos/ 'angry',

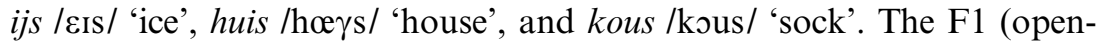
close dimension) and F2 (front-back dimension) values of these values were measured by means of the Praat software (Boersma \& Weenink 2010). A more elaborate discussion of the acoustic and statistical analyses, including the normalization (Lobanov) procedure, can be found in Van der Harst (i.p.).

Figure 5 presents the mean $\mathrm{F} 1$ and $\mathrm{F} 2$ values per region at the midpoint of the eight monophthongal vowels. At first sight the regional differences seem to be restricted, except for (I) and $(\varepsilon)$. However, the statistical analyses show that there are systematic differences within each country for almost all monophthongal vowels. Table 3 gives an overview of the significant effects of the factors country and region for F1 and F2. The vowels are ordered in decreasing order of effect size (the strength of the effect). The only vowel that does not yield a significant difference between Belgian and Netherlandic Dutch is (i). It should also be noted that only two weak effects (out of 16 possible ones) of the age factor show up, for F1 of (a) and F2 of (o). The conclusion is that the vowel 


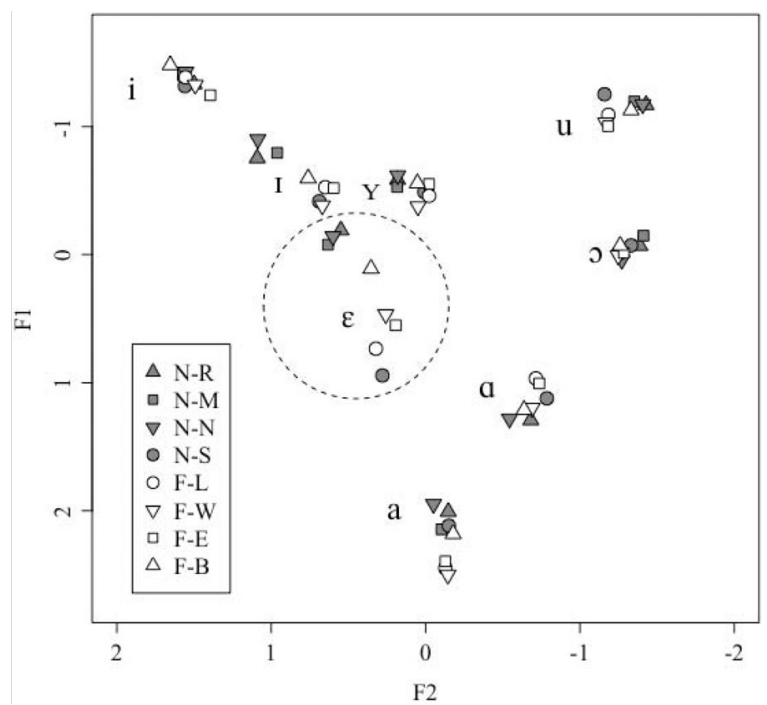

Figure 5. Mean values of normalized F1 and F2 of eight monophthongs in the word list data of VTD, split up per region. The means are calculated on the basis of the formant values at the vowels' midpoints $(\mathrm{n}=160, \mathrm{k}=1280)$.

quality of the Belgian Dutch monophthongs differs from the Netherlandic ones in a systematic and stable way:

Table 3. Significant effects of a series of analyses of variance of the factors country and region (nested under country) for F1 and F2 of eight monophthongal vowels in VTD, measured at the midpoint. The vowels are orded in decreasing order of effect size.

\begin{tabular}{llllllll}
\hline country F1 & $\varepsilon$ & a & I & u & Y & a & \\
country F2 & I & $\varepsilon$ & u & Y & 0 & & \\
region F1 & $\varepsilon$ & I & Y & i & & & \\
region F2 & I & $\varepsilon$ & u & Y & a & i & 0 \\
\hline
\end{tabular}

Figure 6 presents the mean $\mathrm{F} 1$ and $\mathrm{F} 2$ values per region at the onset ( 25 percent) and offset ( 75 percent) of the three diphthongs. Systematic differences between the countries and regions show up, and are supported by the statistical analyses (Van der Harst i.p.). The most outspoken differences are found in the F1 values at the diphthong onset. Netherlandic diphthongs have a more open onset than the Belgian ones, with F-B being more similar to the N-R, N-M and N-N regions in the Netherlands, and N-S being more similar to the Belgian regions. Furthermore, 
similar differences in the distances between the onset and offset are found, reflecting differences in the degree of diphthongization. Regions with a more open onset tend to show stronger diphthongization. Finally, there are some striking differences in the F2 of the offset of (œy). In N$\mathrm{R}, \mathrm{N}-\mathrm{M}$ and N-S (œy) glides to a central vowel, in the other regions to a more front vowel. The results support the existence of an autonomous Belgian standard for the pronunciation of diphthongs, but they also question it. First, the diphthongs in the core area of standard language developments in Flanders (F-B) are rather similar to the realization in $\mathrm{N}-\mathrm{R}, \mathrm{N}-\mathrm{M}$ and N-N, except for the offglide of (œy). Second, N-S clusters with the regions in Flanders, suggesting a north-south division (north and south of the so-called big rivers), instead of one between Belgian and Netherlandic Dutch.

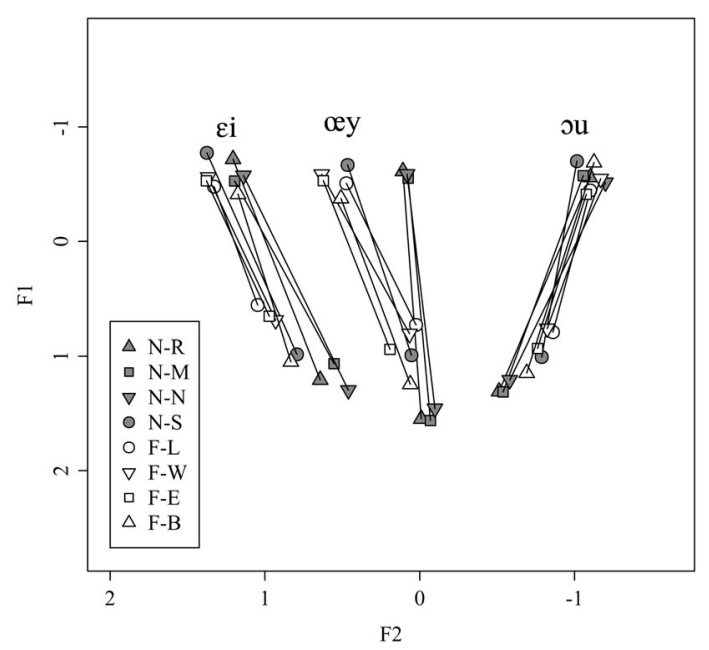

Figure 6. Mean values of normalized F1 and F2 at the onset and the offset of the diphthongs (ei), (ui) and (ou) in the word list data of VTD, split up per region $(\mathrm{n}=160, \mathrm{k}=480)$.

Figure 7 presents the mean F1 and F2 values per region at the onset (25 percent) and offset (75 percent) of the three long mid vowels (e), (ø) and (o). A very sharp distinction between Belgian and Netherlandic Dutch shows up, which is supported by the statistical analyses (Van der Harst i.p.). The long mid vowels are diphthongized (defined as a change on F1) in the Netherlands - with weaker diphthongization in N-S - but are monophthongs in Belgium. ${ }^{8}$ This pattern is confirmed by the DRD data, the real time study of broadcasters' speech. Figure 8 presents a diphthongization index for the variables (e) and (o) in Belgian and Neth- 


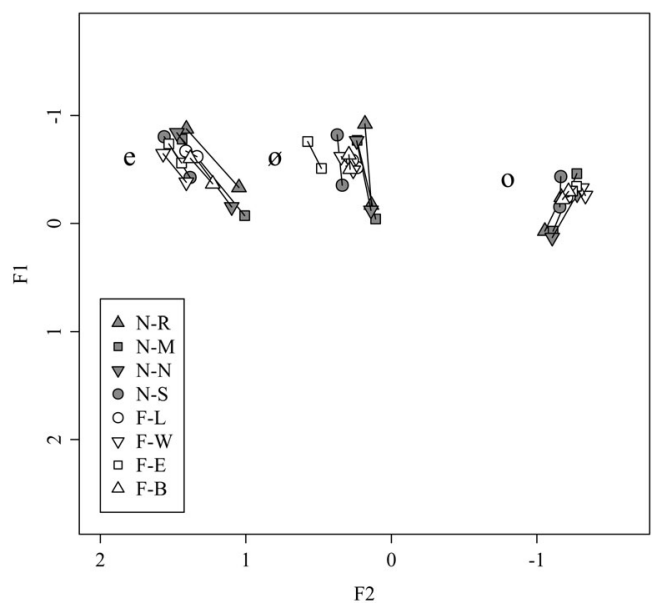

Figure 7. Mean values of normalized F1 and F2 at the onset and the offset of the long mid vowels (e), (ס) and (o) in the word list data of VTD, split up per region $(\mathrm{n}=160, \mathrm{k}=480)$.

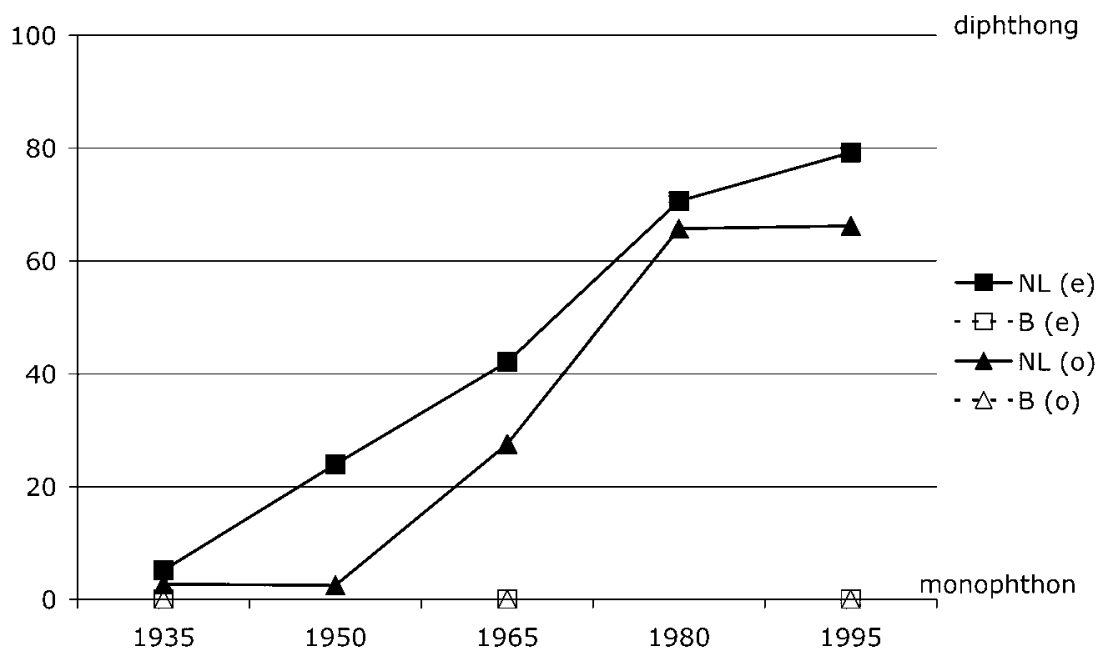

Figure 8. Pronunciation of the long mid vowels (e) and (o) in The Netherlands and Flanders between 1935 and 1995 (DRD). $(\mathrm{n}=68, \mathrm{k}=963$ for $(e)$ and $\mathrm{k}=919$ for $(\mathrm{o}))$.

erlandic Dutch between 1935 and 1995 (Van de Velde 1996a, 1996b). Three variants were distinguished in an auditory transcription: monophthong - weak diphthong - moderate diphthong. A score of 0 indicates 
that all realizations are monophthongal, which is the case for Belgian Dutch in all periods. The maximum score is 100. In Netherlandic Dutch, both (e) and (o) were still monophthongs in 1935. The diphthongization process starts with (e) in 1950 and is followed by (o) in 1965. It is a change in progress in Netherlandic Dutch, which did not spread to Belgian Dutch.

Systematic differences between the countries and/or regions were found in the acoustic analyses of all 14 vowels followed by /s/, but the overall structure of the vowel system is approximately the same. ${ }^{9}$ The largest (and most salient) difference between Belgian and Netherlandic Dutch is found in the long mid vowels. The other differences are much more subtle, and most of them appear to be Belgian-Netherlandic differences below the level of consciousness.

\subsection{Fricative devoicing}

Dutch has three voiced-voiceless fricative pairs /v/-/f/, /z/-/s/ and $/ \mathrm{y}-/ \mathrm{x} /$ and devoicing of the phonologically voiced ones is generally seen as a change in progress in Netherlandic Dutch. They belonged to the core variables in DRD. Figure 9 presents the index for (v), (z) and (g) in syllable initial position in a sonorant environment. On the basis of an auditory transcription (without visual inspection of the spectrum) three variants were distinguished: voiceless, partially voiced, and fully voiced. The index scores on the vertical axis range from 0 (all tokens are voiceless) to 100 (all tokens are fully voiced). The results are split up by period (horizontal axis), fricative (different symbols), and country (dotted line for Belgium, full line for the Netherlands). The voice characteristics of (g) yield a striking result. In both countries there is strong devoicing. In Belgian Dutch the patterns seem stable; in Netherlandic Dutch it looks as if the process of devoicing of the back fricative more or less reached completion in 1950. In the Netherlands, (v) and (z) show a similar pattern, with a breakthrough of the devoicing process after 1965. Surprisingly, devoicing of (v) and (z) also shows up in Belgian Dutch in 1995, but given an almost hostile attitude towards the Netherlandic pronunciation in Flanders since the 1980s, it is very unlikely that this is to be interpreted as an example of accommodation to the Netherlandic standard. For a more detailed discussion we refer to Van de Velde, Gerritsen \& Van Hout (1996). Nevertheless, the results for fricative devoicing called for more research in VTD.

Part of the VTD study aimed at eliciting the participant's 'best' realization of all word initial consonants. The participants were asked twice to read the 17 logatoms, covering the Dutch word initial consonants, in the same linguistic context, and presented one by one. The analyses are 


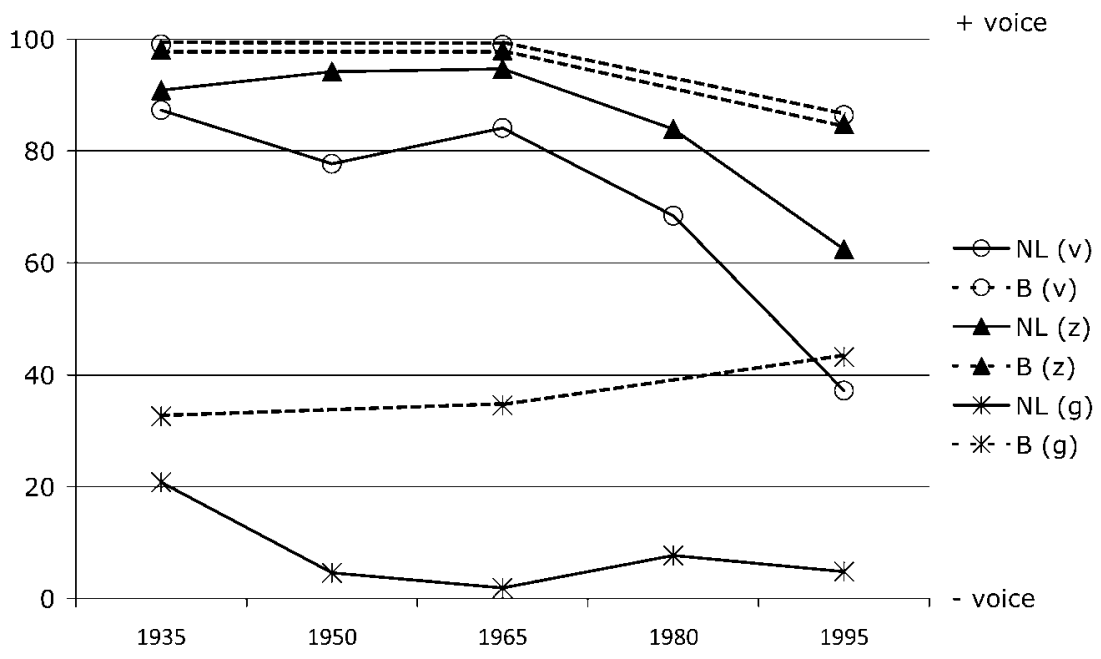

Figure 9. Devoicing of $(v),(z)$ and $(g)$ in Belgian and Netherlandic Dutch between 1935 and 1995 (DRD); $\mathrm{n}=68, \mathrm{k}=2676$ for $(v), \mathrm{k}=2489$ for $(z)$ and $\mathrm{k}=2441$ for $(\mathrm{g})$.

based on 960 tokens of (v), (z) and (g) (160 speakers $\times 3$ variables $\times$ 2 realizations). Trained phoneticians made a consensus transcription on the basis of an auditory analysis and a visual interpretation of the spectrum. Three variants were distinguished again: voiceless, partially voiced, and fully voiced. The index scores range from 0 (all tokens are voiceless) to 100 (all tokens are fully voiced). More details on the methodology and an elaborate discussion of the results can be found in Van de Velde \& Van Hout (2001). The results, split up by fricative and region, are presented in figure 10. For all variables, there were significant differences between Belgian and Netherlandic Dutch. In all cases there is stronger devoicing in the Netherlands, but it should be noted that the devoicing of $(\mathrm{v}),(\mathrm{z})$ and $(\mathrm{g})$ is prominently present in Belgian Dutch. The difference between the two varieties is the smallest for (g), with an index of 35.6 (B) vs. 26.9 (NL). Note that the index scores for the Netherlands are much higher than those in the spontaneous speech data presented in figure 9, but this difference might be due to the stylistic differences between both sets of speech data, as in the logatoms monitoring is extremely high and the focus of the speaker is on pronouncing a standard realization of the consonant. ${ }^{10}$ The differences are larger between Netherlandic (53.1) and Belgian (67.5) (z) and are most outspoken for (v), with a mean score of 41.9 for the Netherlandic and 74.1 for the Belgian speakers. In the Netherlands, regional differences show up for 


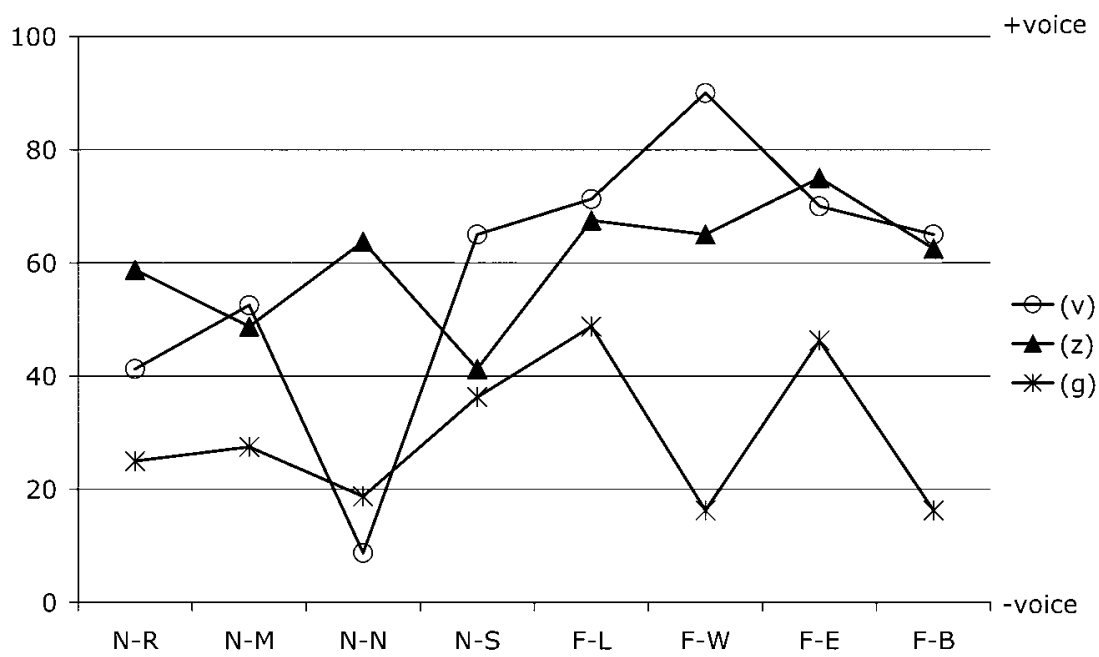

Figure 10. Voice characteristics of $(v),(z)$ and $(g)$ uttered in a carrier sentence, split up by region $(\mathrm{n}=160, \mathrm{k}=960)$.

(v) and in Flanders for (g) and (v). In section 4.5 we will come back to other characteristics of the back fricatives. We focus here on (v) and answer the question of whether the devoicing observed in Belgium and the Netherlands is, from a phonetic point of view, the same process. What is the acoustic implementation of the contrast between $/ \mathrm{v} /$ and $/ \mathrm{f} / ?^{11}$

Kissine, Van de Velde \& Van Hout $(2003,2005)$ present detailed acoustic analyses of both (f) and (v) from the same data set. Tokens of the voiceless counterpart (f) from the same logatom reading task were incorporated in the analysis. A comparison enables us to figure out whether the phonemic contrast between / $/$ / and / $/$ / is preserved and implemented in the same way in Belgian and Netherlandic Dutch and across their regional varieties. Figure 11 presents the results of the acoustic measurement of pitch (F0) of (v) and (f) ( $k=320$ for both linguistic variables). The presence of periodicity was evaluated between the minimum and maximum pitch values of the speaker within the specific utterance and computed with intervals of $10 \mathrm{~ms}$. To obtain a relative measurement of periodicity (voicing) expressed in a percentage, the number of samples with pitch was divided by the total number samples and multiplied by 100. Due to the presence of transitions to the preceding and following vowel, the (f) realizations contain on average about 20 percent of voicing. There is no difference between Belgian and Netherlandic Dutch. A phonetic transcription shows that this is not due to a voiced pronunciation of the fricatives (see Kissine et al. 2003, 2005). The acoustic mea- 


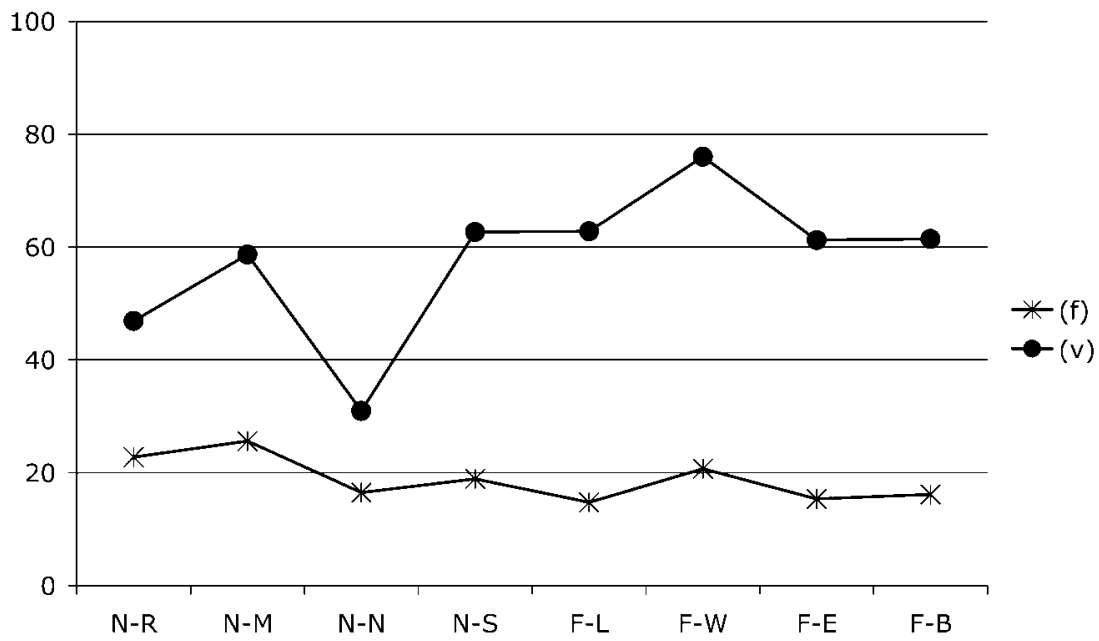

Figure 11. Percentage voicing (acoustic measurements of $F 0)$ in $(f)$ and $(s)$ in word initial position in the logatoms of VTD, split up by region $(\mathrm{n}=160$, $\mathrm{k}=640)$.

surements of (v) reveal the same differences as the phonetic transcription: more devoicing in the Netherlands ( 49.8 percent periodicity) than in Belgium (63.5 percent periodicity) and regional differences within each country. Figure 11 suggests that fricative devoicing will result in a merger of $/ \mathrm{v} /$ and $/ \mathrm{f} /$ in both Netherlandic and Belgian Dutch, which is nearly complete in N-R.

However, when we look at figure 12, which presents measurements of the duration of (f) and (v), we have to modify this view. One has to be careful with the overall durations, as they can be caused by regional differences in speech rate. ${ }^{12}$ However, if one focuses on the differences in duration between (v) and (f) per region, one can normalize for this effect, as one might assume that both variables are affected in a similar way by regional speech rate differences. Overall, there are no significant differences for the duration of (v) between Belgian (138.5 ms) and Netherlandic Dutch (141.7 ms). However, Belgian Dutch (f) is significantly, and more than $20 \mathrm{~ms}$., longer than Netherlandic Dutch (f): $186.4 \mathrm{~ms}$ vs. $165 \mathrm{~ms}$. In other words, Belgian Dutch speakers play with the length distinction and seem to shorten $/ \mathrm{v} /$ and lengthen /f/ to preserve the contrast between the consonants, which at least suggests that an apparently similar change in both varieties follows different phonetic paths. Once more, N-S seems to be more similar to the Belgian regions than to the other Netherlandic ones. Kissine, Van de Velde \& Van Hout (i.p.) discuss 


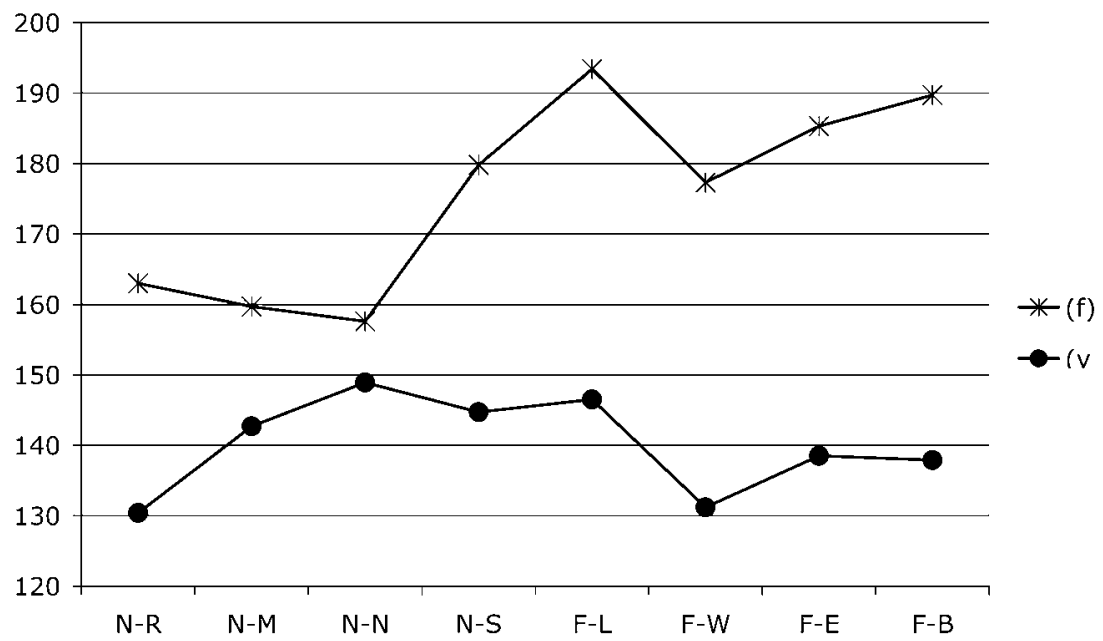

Figure 12. Duration in $m s$ of $(f)$ and $(s)$ in word initial position in the logatoms of VTD, split up by region $(N=160, \mathrm{k}=640)$.

the regional differences in the implementation of the $/ \mathrm{v} /-/ \mathrm{f} /$ contrast in more detail.

Considering the strong devoicing of the fricatives in Belgian Dutch, it is strange that this has not been observed before - except for the back fricative (Debrock 1977, 1978) - either by language users or linguists. However, the phenomenon is confirmed on the basis of a phonetic analysis of other speakers of Belgian Dutch (Verhoeven \& Hageman 2007).

\subsection{Place of articulation of the back fricative}

The distinction between so-called hard and soft realizations of $/ \mathrm{\gamma} /$ and / $\mathrm{x} /$ has often been claimed to be one of the most salient North-South differences in the pronunciation of both standard and non-standard Dutch. Nowadays, it has developed into a stereotype. Speakers from north of the big rivers are claimed to speak with a 'hard g', speakers from south of these rivers - Flanders and the southern provinces of the Netherlands - speak with a 'soft g'. In section 3.4 it was shown that $/ \mathrm{y} /$ is predominantly voiceless in Dutch. According to Van de Velde (2006) the difference between hard and soft is determined by place of articulation: uvular realizations are always considered hard, palato-velar and palatal realizations are always considered soft by Netherlandic listeners. Only in velar realizations does voicing play a role: voiced velar fricatives are mainly classified as soft, voiceless velar fricatives mainly as hard. 


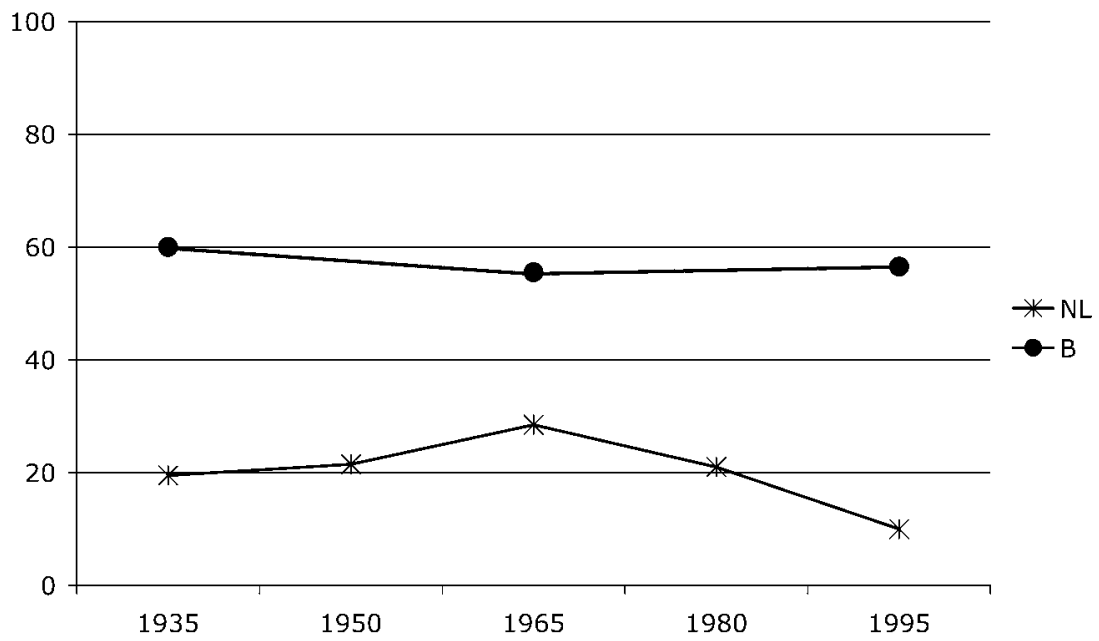

Figure 13. Place of articulation of $(g)$ in Belgian and Netherlandic standard Dutch, between 1935 and 1995 (DRD). The index scores range from 0 (uvular) to 100 (palato-velar) $(\mathrm{n}=68, \mathrm{k}=2441)$.

Figure 13 presents the index score for place of articulation of $(\mathrm{g})$ in DRD $(n=68, k=2441)$. Three variants were distinguished: uvular, velar and palato-velar. The index scores range between 0 (always uvular) and 100 (exclusively palato-velar), and are split up for period and country. Belgian Dutch has a more advanced front realization of $(\mathrm{g})$ than Netherlandic Dutch and remains stable over time. Velars are by far the most frequent variants in Belgian Dutch; uvulars are rare. In Netherlandic Dutch we see a light decrease in the index score in 1995, which implies that uvular realizations are becoming more frequent than velar ones. Palato-velars are rare in Netherlandic Dutch (see Van de Velde 1996: 105). Once more, there is an obvious and systematic difference between Belgian and Netherlandic Dutch. We can have a closer look at the present-day differences on the basis of the transcription of the place of the articulation of the (g) logatoms of VTD described in Section 4.4 $(n=160, k=320)$.

Figure 14 presents the index scores, split up by region. The scores are calculated in the same way as those used for figure 13 .

Figure 14 confirms the North-South split sketched above. N-S has much more of a front realization than the other Netherlandic regions, and is linked more to the Belgian regions, especially to F-L, with which it forms the Limburg dialect region and where almost exclusively velar and palato-velar realizations were noted. N-N and N-R are exclusively 


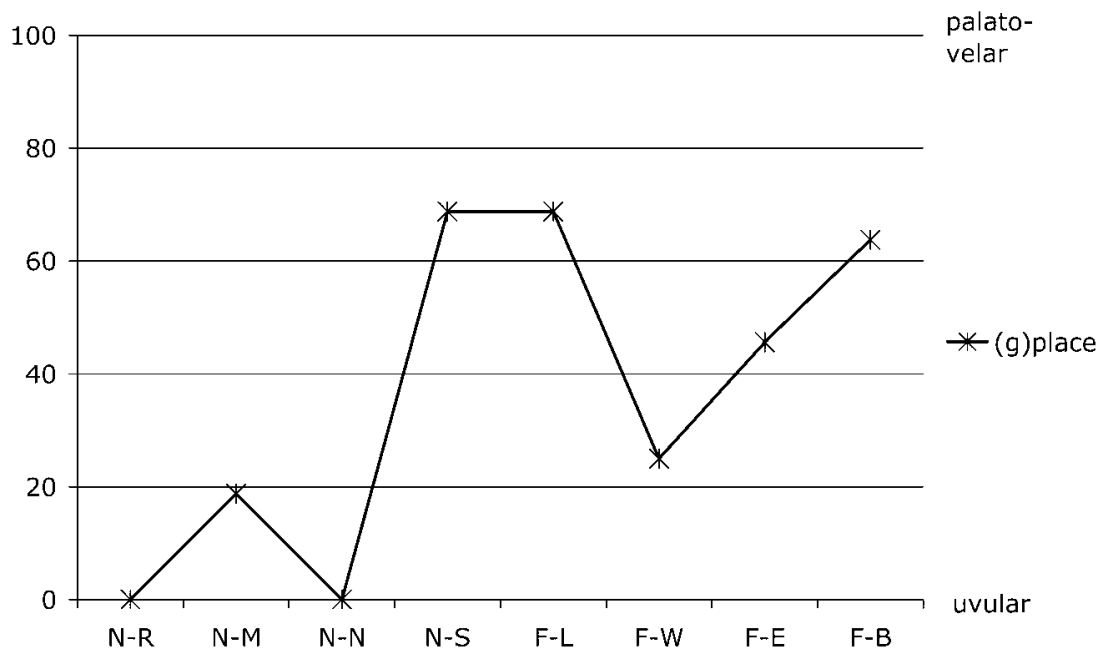

Figure 14. Place of articulation of $(g)$ in word initial position in the logatoms of VTD, split up by region. The index scores range from 0 (uvular) to 100 (palatovelar); $\mathrm{n}=160, \mathrm{k}=320$.

uvular in the Netherlands; in N-M there is a mixture of uvular and velar realizations. Remarkable in Belgian Dutch are the lower index scores in F-E and F-W. Especially in the latter area a lot of uvular fricatives show up. These variants do not show up in the dialects, but they are used in standard Dutch as a strategy to avoid dialectal [h]. For more details we refer to Van der Harst \& Van de Velde (2007). A first acoustic analysis of these data is presented in Van der Harst, Van de Velde \& Schouten (2007).

\subsection{Word final n-deletion}

The pronunciation of word final /on/ has been widely discussed in phonologies and pronunciation guides of Dutch, but almost none of the claims in these works was based on systematic, quantitative research. In the normative literature it is often stated that $/ \mathrm{n} /$ should be deleted in standard Dutch pronunciation, except in prevocalic position. However, some authors are more tolerant and accept both [ə] and [ən] as standard pronunciations, pointing to the regional background of the speakers, the right hand environment and the morphological status of /ən/ as the main sources of variation. In his real time study of Belgian and Netherlandic Dutch Van de Velde (1996: 145-157) limited the variable (n) to the suffix -en in plural nouns, plural finite verb forms, and infinitives $(n=68$, 


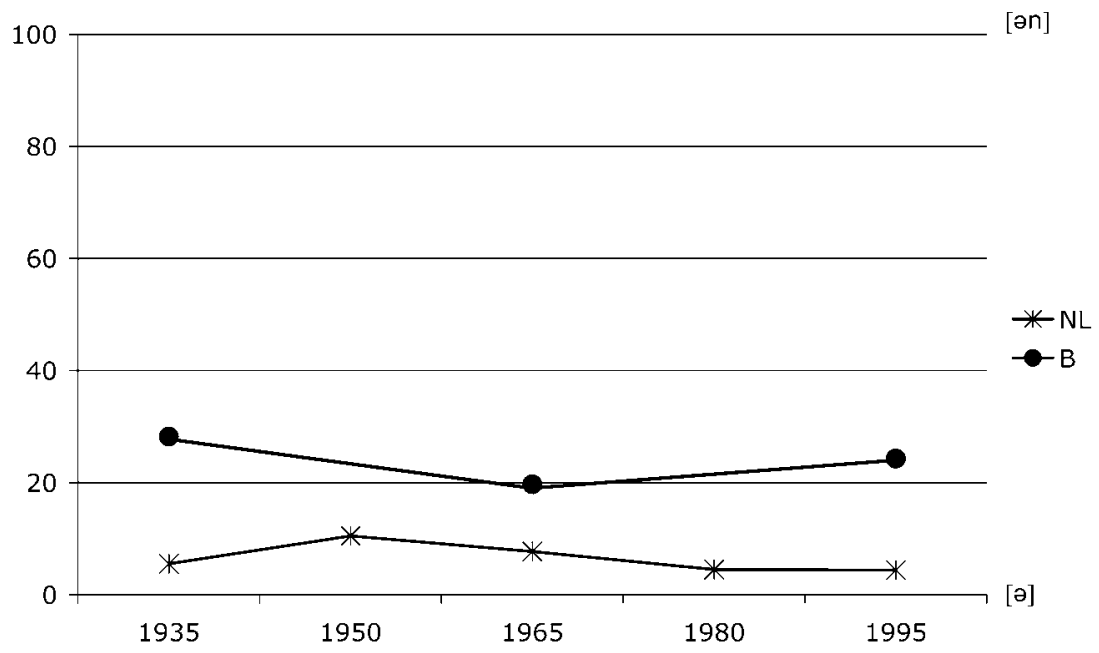

Figure 15. Word final (n) in Belgian and Netherlandic standard Dutch, between 1935 and 1995 (DRD). The index scores range from 0([a]) to 100 ([ən]).

$k=1978)$. For the calculation of the index scores two variants were distinguished: with and without a nasal element. The index scores, split up by country and period, are presented in figure 15. An index score of 0 means that (n) is exclusively pronounced as [ə], an index score of 100 means that there is always a nasal element. There is a significant difference between Belgian and Netherlandic Dutch, which is in line with the expectations. There is less nasal deletion by the Belgian broadcasters. It should also be noted that deletion rates are extremely high in these spontaneous speech data, especially in the Netherlands. However, there is no effect of period: (n) appears to be a stable variable over time.

Figure 16 presents the results from the study of $n$-deletion in two speech styles in the corpus of regional variation in contemporary standard Dutch. For the sake of comparison between the two speech styles, the study of (n) is limited to infinitives. The tokens for spontaneous speech were selected from an interview with the teachers about their job and everyday life $(n=160, k=9254)$. Before, they had performed a reading task, which focused on $n$-deletion and schwa-insertion. The participants were unaware of these variables. The index scores are based on five observations per speaker of (n) in infinitives $(n=160, k=800)$ and are calculated in the same way as for the data presented in figure 15. A more elaborate study of the role of linguistic factors in $n$-deletion in reading style is presented in Van de Velde \& Van Hout (2001, 2003). 


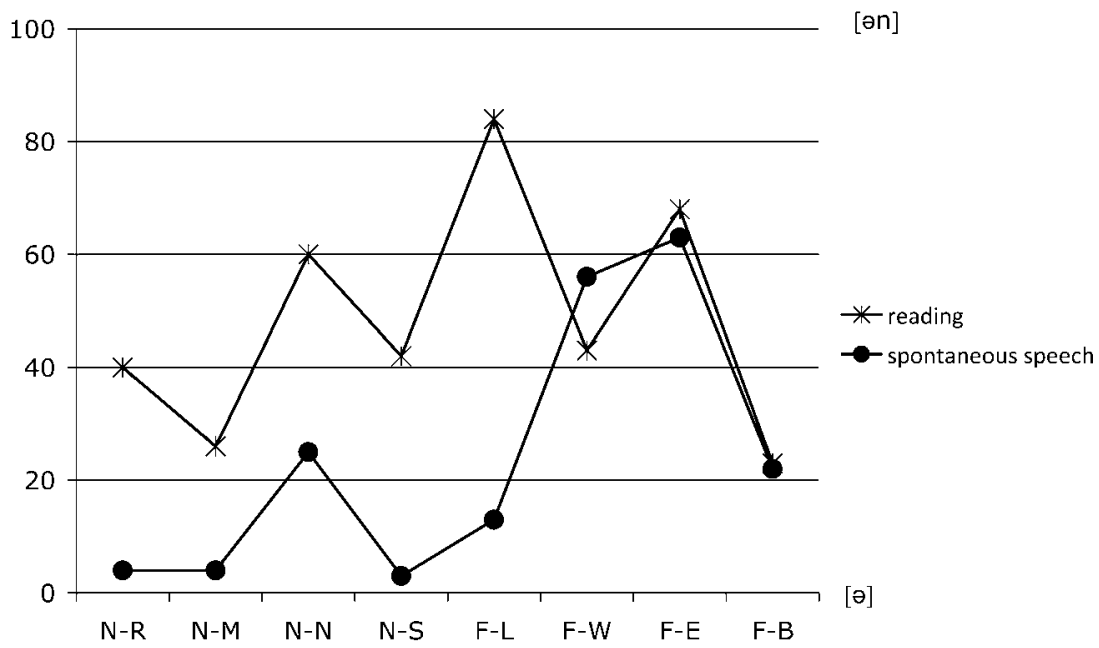

Figure 16. Word final $(n)$ in infinitives for Netherlandic and Belgian Dutch in VTD, split up by style and region. The index scores range from 0 ([a]) to 100 ([ən]); $\mathrm{n}=160, \mathrm{k}=800$ for reading and $\mathrm{k}=9254$ for spontaneous speech.

The spontaneous speech data refine the insights into $n$-deletion in standard Dutch. First, it should be noted that there are large regional differences in each national variety. These differences are in line with the expectations on the basis of dialect data: less $n$-deletion in N-N than in the other Netherlandic regions and less $n$-deletion in F-W and F-E than in the other Belgian regions. Second, the results confirm the differences observed between Netherlandic and Belgian Dutch, with on average much higher $n$-deletion rates (low index scores) in the Netherlands. Furthermore, Flemish regions (F-L and F-B) with high $n$-deletion rates (low index scores) still have higher scores than $n$-deleting regions in the Netherlands (N-N, N-M, and N-S). However, in reading style a very different and surprising picture shows up. In Netherlandic Dutch the nasal is realized much more in reading style than in spontaneous speech. In Flanders, this difference does not show up systematically: no difference between the styles in F-B and F-E, much more realization in F-L, and more deletion in F-W. This result contradicts the popular belief also among linguists - that Belgian speakers of standard Dutch stick much more to spelling pronunciation than Netherlandic speakers. Departing from the idea that the Belgian teachers of Dutch - who were all trained in the pronunciation of standard Dutch during their study speak most standard in the tasks with highest speech monitoring, the data suggest that there are two competing norms in Belgian standard 
Dutch: [ə] in F-B and F-W, and [ən] in F-L and F-E. In F-B both the vernacular (in the sense of endogenous in the dialects) and standard realizations are [ə], hence there are no differences between the speech styles. In F-W the vernacular realization is [ən] and the speakers partially succeed in suppressing [n]. In F-E, with endogenous [ən], it looks as if the target standard realization is [ən], as it is clearly the case in F-L, where the endogenous form is [ə]. However, this interpretation is still speculative and more research into the linguistic conditioning of this process is necessary to disentangle the complex regional and stylistic patterns. Finally, it should be noted that F-B, the core area for Belgian Dutch, has the highest rate of $n$-deletion, and seems to converge most with Netherlandic Dutch.

\section{$4.7|r|$}

The $/ \mathrm{r} /$ is by far the most variable sound in Dutch, both between and within speakers, and the allophonic variation is determined by both internal and external factors. Furthermore, $/ \mathrm{r} / \mathrm{is}$ involved in different changes in progress in Belgium and the Netherlands: the rise of uvular $/ \mathrm{r} /$ in colloquial Belgian Dutch (Tops 2009) and of approximant $/ \mathrm{r} / \mathrm{in}$ Netherlandic Dutch (Van Bezooijen, Kroezen \& Van den Berg 2002; Van Bezooijen 2005). The allophones of / $\mathrm{r} /$ differ in both place and manner of articulation. We will focus our discussion on two dimensions: place of articulation (rfront) and degree of consonantality (rcons). For a more detailed discussion we refer to Van de Velde (1996) and Van de Velde \& Van Hout (1999).

Figure 17 presents the results for postvocalic (r) in DRD. The index scores range from 0 (no front realizations) to 100 (only front realizations). There is a significant difference between Netherlandic and Belgian Dutch, the former variety having more back realizations. There are no significant changes over time in the standard spontaneous speech of broadcasters. The Belgian speakers all exclusively have front realizations, except for a 1935 speaker who mixes front and back realizations and a 1995 speaker who always speaks with a uvular. ${ }^{13}$ In Netherlandic Dutch there is considerable inter- and intraspeaker variation. Furthermore, it should be noted that front realizations are dominant among Dutch broadcasters in all periods, contrary to several unsystematic observations in the literature. figure 18 presents the index scores for consonantality. There is an obvious and significant difference between the two national varieties. In Belgian Dutch the index scores are 100 or very close to it: almost all realizations of (r) are consonantal. In Netherlandic Dutch the consonantality of (r) is much lower, as there are a lot of approximant and vocalic realizations. There is a significant decrease in 


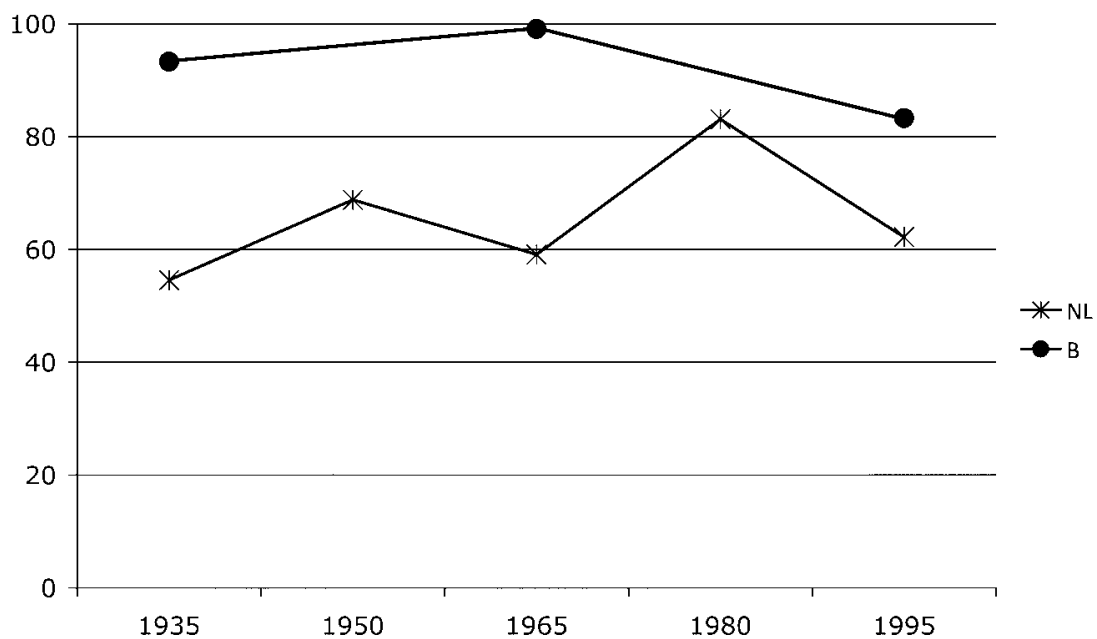

Figure 17. Place of articulation of $(r)$ in Belgian and Netherlandic Dutch between 1935 and 1995 (DRD). The index score ranges from 0 (back) to 100 (front); $\mathrm{n}=68, \mathrm{k}=1304$.

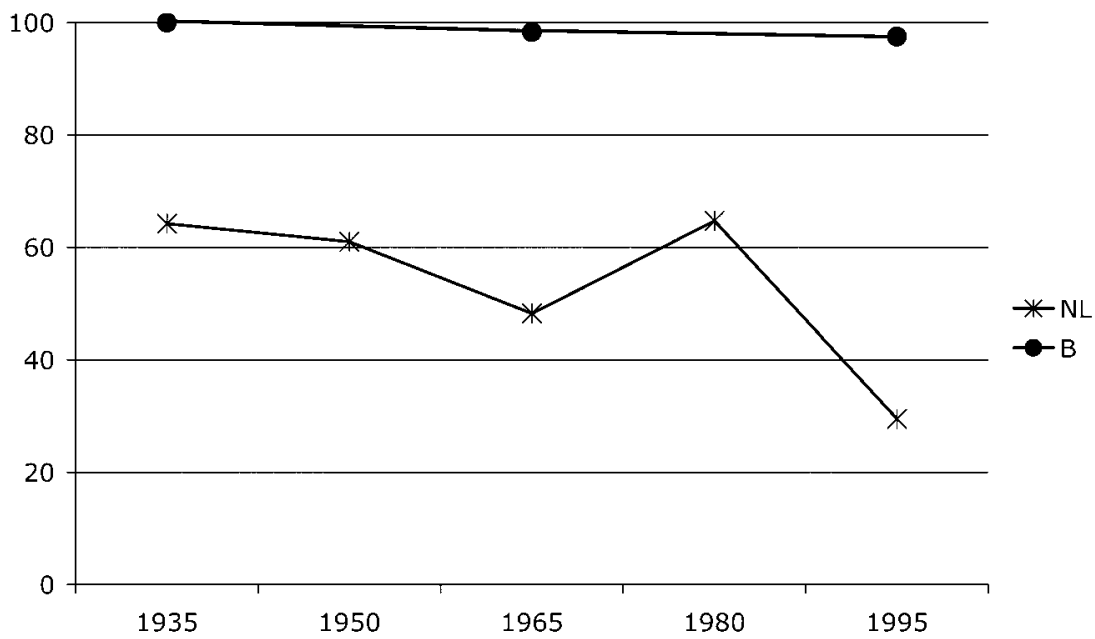

Figure 18. Consonantality of $(r)$ in Belgian and Netherlandic Dutch between 1935 and 1995 (DRD). The index score ranges from 0 (- consonantal) to 100 $(+$ consonantal $) ; \mathrm{n}=68, \mathrm{k}=1304$.

consonantality of (r) in the last period. Belgian Dutch does not follow the developments in Netherlandic Dutch. 


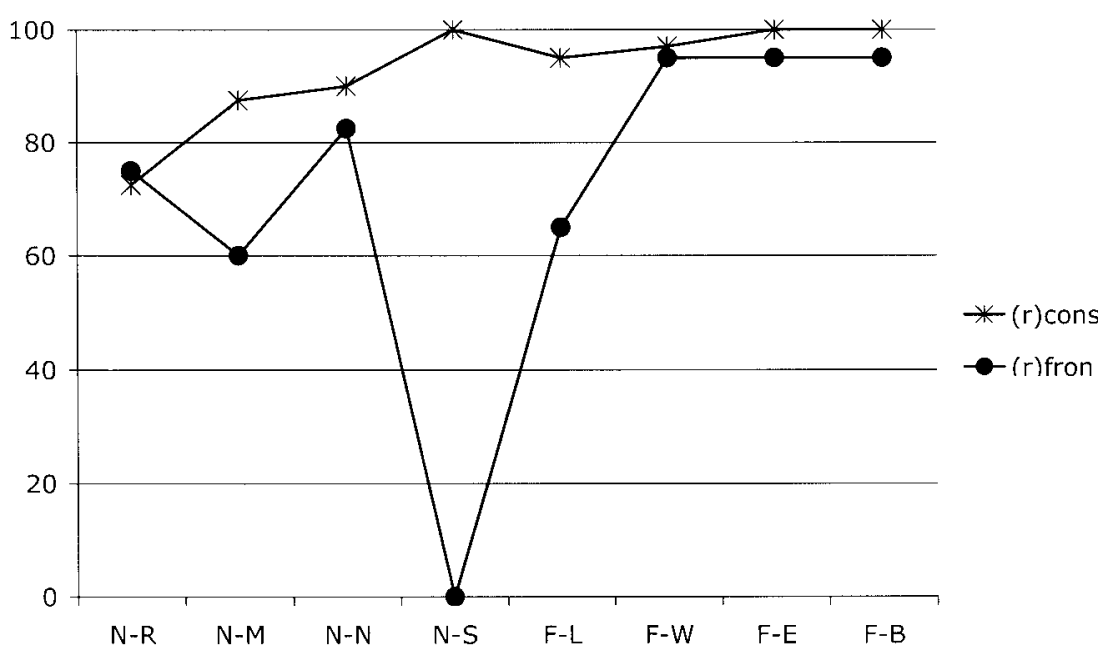

Figure 19. Place of articulation and consonantality of postvocalic ( $r$ ) in logatoms in $V T D$, split up by region; $\mathrm{n}=160, \mathrm{k}=320$.

The index scores for place of articulation and consonantality of postvocalic (r) in VTD are presented in figure 19. The results for (r-front) confirm and refine the insights on the basis of DRD. Belgian Dutch has more front realizations than Netherlandic Dutch and front realizations are dominant, except in N-S, which has only back realizations of (r). The most similar cross-border region F-L also has the lowest score (i.e., the most back realizations) in Flanders. Tops (2009) showed that uvular realizations are no longer limited to the Limburg area, but are spreading rapidly in different parts of Flanders in colloquial speech.

In the Netherlands, the scores (r-cons) are very high in comparison with the 1995 results in DRD (figure 18). However, this does not mean that the change observed in DRD and in Van Bezooijen et al. (2002) is stopped or even reversed. The differences can be explained by the nature of the speech data. In DRD spontaneous speech was analysed, in VTD logatoms in which the speakers fully focused on the variable. In Belgium, F-L has a much lower score than the three other regions, due to a fairly large number of uvular approximants.

\section{Has or will Dutch become Flemish?}

Table 4 attempts to summarize the results presented in section 4 . In the lefthand column one can find the phonological variables. For each variable the following questions are answered in four columns: 
(1) Is there a difference between Belgian and Netherlandic Dutch in the real time corpus DRD?

(2) Is there a difference between Belgian and Netherlandic Dutch in the contemporary VTD corpus?

(3) Is there a difference between N-S and F-L, the two neighboring Limburg provinces on both sides of the state border, in VTD?

(4) Is there a difference between N-R and F-B, the two core areas in Belgium and the Netherlands, in VTD?

The answers, based on a combination of statistical testing and interpretation of the variation patterns, are coded as follows:

$=$ the varieties are similar / not different

$\neq$ the varieties are different / not similar

$\approx$ the varieties are different, but tend to be more similar than other combinations (only used for [3] and [4]).

In the column DRD B versus NL there are a number of empty cells for the variables that were not studied in the DRD corpus.

Positive answers to questions (1) and (2) might indicate divergence between Belgian and Netherlandic Dutch. Table 4 shows this pattern for all phonological variables, except for (i) and (n)read. The pervasiveness of this pattern of dissimilarity provides strong evidence for autonomous development in both Belgian and Netherlandic Dutch. The main conclusion of the DRD study was that Netherlandic Dutch had changed a lot between 1935 and 1995 whereas Belgian Dutch had remained stable in the same period. We were able to show that an apparently similar change in devoicing the (v) in Belgian and Netherlandic Dutch is phonetically different by looking at the acoustic implementation of the $\mathrm{v}-\mathrm{f}$ contrast.

There are an overwhelming number of differences between presentday Belgian and Netherlandic standard Dutch, but none of them leads to a different phoneme inventory. Belgian and Netherlandic Dutch share the same vowels and consonants. The phonetic differences observed are allophonic and most of them seem to act below the level of consciousness. This argument counterbalances overstatement of the strength of the autonomous developments in Belgian and Netherlandic Dutch. Other counterarguments against its strength are to be found in the answers to question (3). If Belgian and Netherlandic Dutch are completely autonomous, N-S and F-L, the neighboring Limburg provinces situated along the state border, which are covered under the umbrella of a different national variety, should be different too. However, for a large number of variables there are no differences between N-S and F-L or the two regions tend to be more similar than other regions. N-S and F-L speak- 
Table 4. Summary of the country and region effects for phonological variables in DRD and VTD. The following differences are assessed: (i) Belgian vs. Netherlandic Dutch in DRD; (ii) Belgian vs. Netherlandic Dutch in VTD; (iii) N-S vs. F-L (the Limburg provinces across the state border); (iv) $F-B$ vs. $N-R$ (the two core regions in Belgium and the Netherlands). The following symbols are used: $=$ (very similar), $\neq$ (very different) and $\approx$ (small difference, rather similar). If a cell is left empty the variable is not studied.

\begin{tabular}{|c|c|c|c|c|c|}
\hline & & DRD & VTD & & \\
\hline & & B vs. NL & B vs. NL & N-S vs. F-L & F-B vs. N-R \\
\hline loan words & (a) & & $\neq$ & $\neq$ & $\neq$ \\
\hline & (tie) & & $\neq$ & $\approx$ & $\neq$ \\
\hline & (nasal) & & $\neq$ & $\neq$ & $\neq$ \\
\hline vowels & (i) & & $=$ & $=$ & $\neq$ \\
\hline & (I) & & $\neq$ & $=$ & $\approx$ \\
\hline & $(\varepsilon)$ & & $\neq$ & $=$ & $\approx$ \\
\hline & (a) & & $\neq$ & $\neq$ & $=$ \\
\hline & (a) & & $\approx$ & $\neq$ & $=$ \\
\hline & (0) & & $\approx$ & $\approx$ & $\approx$ \\
\hline & (u) & & $\approx$ & $\approx$ & $=$ \\
\hline & (Y) & & $\approx$ & $=$ & $\approx$ \\
\hline & (ci) & & $\neq$ & $\approx$ & $\approx$ \\
\hline & (œy) & & $\neq$ & $=$ & $\neq$ \\
\hline & (ou) & & $\neq$ & $=$ & $=$ \\
\hline & (e) & $\neq$ & $\neq$ & $\approx$ & $\neq$ \\
\hline & $(\varnothing)$ & & $\neq$ & $\approx$ & $\neq$ \\
\hline & (o) & $\neq$ & $\neq$ & $\approx$ & $\neq$ \\
\hline consonants & (v) & $\neq$ & $\neq$ & $=$ & $\neq$ \\
\hline & (z) & $\neq$ & $\neq$ & $\neq$ & $=$ \\
\hline & (g) & $\neq$ & $\neq$ & $\approx$ & $=$ \\
\hline & $(\mathrm{v}-\mathrm{f}) \mathrm{F} 0$ & & $\neq$ & $=$ & $\neq$ \\
\hline & (v-f)dur & & $\neq$ & $\approx$ & $\neq$ \\
\hline & $\mathrm{g}$ (place) & $\neq$ & $\neq$ & $=$ & $\neq$ \\
\hline & (n)spon & $\neq$ & $\neq$ & $=$ & $\approx$ \\
\hline & (n)read & & $=$ & $\neq$ & $\neq$ \\
\hline & (r)front & $\neq$ & $\neq$ & $\approx$ & $\neq$ \\
\hline & (r)cons & $\neq$ & $\neq$ & $\neq$ & $\neq$ \\
\hline
\end{tabular}

ers share the same dialect background, and this is also audible in their standard speech, at least for some variables. For other variables they seem to accommodate to the standard speech spoken in the other regions of their respective countries. The differences between N-S and F-L could also indicate a North-South distinction (below and above the big rivers) instead of Belgian vs. Netherlandic Dutch, but this is not the case for, for example, (g)place, (r)front, (n)spont, (i), (u) and (o). Another counterargument for a definite autonomous development in Belgian Dutch is found in the answers to question (4), the similarities between F-B and N-R. If, of all the Flemish regions, its core area (Brabant) is closest 
to the core area in the Netherlands (Randstad), this closeness must be interpreted as a straightforward indication of ongoing convergence between Netherlandic and Belgian Dutch. The standards maintain their old independent relationship. As the number of age effects is small in the data analyzed in VTD, further research on the basis of less monitored speech will be necessary to interpret the resemblances between F-B and N-R more accurately. However, it seems that most variables for which we find this resemblance act below the level of consciousness. For the most salient differences between Netherlandic and Belgian Dutch the pronunciation of loan words, place of articulation of $(\mathrm{g}), \mathrm{r}$ (cons) and diphthongization of (e), ( $\varnothing)$ and (o) - clear differences between N-R and N-S show up, suggesting an autonomy of Belgian Dutch for variables above the level of consciousness.

The differences observed clearly mark the development of two divergent pronunciation standards, based on different linguistic (re)sources, but on the lexical level patterns of convergence are observed between Belgian and Netherlandic Dutch (Geeraerts, Grondelaers \& Speelman 1999). The relationships and the connectivity between both varieties will remain strong, based on their shared linguistic history and shared language policy, but also because they are neighbors, shared infrastructure and economic links. As such, Dutch is not different from its two closest neighbors German and English. A shared linguistic repertoire is at the heart of pluricentric languages. Pluricentric powers will make sure that Flemish remains Dutch, although not Netherlandic.

We would like to give the final conclusion to Willemyns (2003: 119):

Predictions, therefore, are not very helpful, except for this one: the linguistic evolution of Dutch in the twenty-first century promises to be an exciting and thrilling affair, worthwhile to participate in and to be closely observed!

Utrecht University

Université Libre de Bruxelles Radboud University Njjmegen

\section{Notes}

1. We will use the adjective Netherlandic to refer to the Netherlands, and Belgian to refer to Belgium and/or Flanders.

2. In 1993 Belgium became a fully-fledged federal state and all responsibilities concerning the Dutch language were transferred to the Flemish Community. In 2004 Surinam joined the Dutch Language Union as an associate member.

3. For convenience sake in the figures we use 1995 as the $5^{\text {th }}$ period of the study, although the most recent recordings are from 1993. A new sample is to be collected in 2010. 
4. The number of selected Belgian broadcasters is smaller, as there have always been far fewer Belgian (Flemish) broadcasters than Dutch ones. Furthermore, the Belgian radio archive is also much smaller than the Dutch national sound archive.

5. It should be noted that most of the Belgian teachers were trained in the tradition of the propagation of the Netherlandic standard language on the lexical and grammatical level. For pronunciation the speech of the broadcasters of the Belgian radio and television stations served as a role model, which is clearly different from the Netherlandic standard (see section 3.1).

6. In tasks with high monitoring, language variation is reduced. This might explain why age and sex differences do not frequently show up in our analyses of data from word lists and carrier sentences in the VTD corpus. However, significant differences between the Netherlands and Belgium and between regions within these countries show up frequently.

7. The combination /ys/ exists in a couple of proper names, but the length and quality of the vowel varies a lot in these names.

8. There are some spectral changes that drop over time in the Belgian Dutch long mid vowels, but these are mainly on the F2 dimension. The spectral changes for F1 are comparable to those found in other monophthongal vowels (see Van der Harst i.p.).

9. In some regions - both in the Netherlands and Flanders - /u/ is not the most back vowel in the system.

10. It is not clear how the differences in transcription technique might interfere. On the one hand, the visual inspection of the spectrum might lead to an increase of intermediate variants, as tokens with a short period of devoicing might auditorily pass as fully voiced but are now classified as partially voiced. On the other hand, the software enables us to isolate the variable much more easily from its linguistic environment than can be done with an audio tape, and will probably result in more voiceless classifications.

11. Note that the possible loss of the phonemic voicing contrast cannot be tested on the back pair $/ \mathrm{\gamma} /-/ \mathrm{x} /$, as the latter does not occur in prevocalic position, except in a couple of loan words and in the cluster $/ \mathrm{sx} /$.

12. See Quené (2008) for an analysis of the spontaneous speech of the same speakers, showing that the Belgian Dutch participants speak more slowly than the Dutch ones.

13. Note that the 1935 speaker with mixed /r/ was instructed by the Belgian broadcasting corporation to speak with an alveolar [r]. The 1995 speaker was not allowed to become a television journalist due to his uvular [R] (Van de Velde 1996: 126).

\section{References}

Arnold, Jennifer, Renée Blake, Brad Davidson, Scott Schwenter \& Julie Solomon (eds.). 1996. Sociolinguistic variation: Data, theory and analysis. Stanford: CSLI Publications.

Aspeslagh, Rob, Filip Boen, Henk Dekker, Hub Linssen, Roland Pepermans, Norbert Vanbeselaere \& Vincent Yzerbyt. 2000. België en Nederland in beeld. Wat weten, denken en vinden jongeren in België en Nederland van elkaars landen en bevolkingen? 's-Gravenhage: Nederlands Instituut voor Internationale Betrekkingen Clingendael. Een empirisch onderzoek in opdracht van de Belgisch-Nederlandse vereniging. http://www.clingendael.nl/publications/2000/20000500_cli_pap_aspeslagh.PDF (accessed 10 May 2010).

Baranowski, Mariej, Uri Horesh, Keelan Evans \& Giang Nguyen (eds.). 2005. Penn Working Papers in Linguistics 10.2. Selected Papers from NWAVE 32. Philadelphia University of Pennsylvania. 
Boersma, Paul \& David Weenink. 2010. Praat. Doing phonetics by computer. www.praat.org.

Broekhuis, Hans \& Paula Fikkert (eds.). 2002. Linguistics in the Netherlands 2002. Amsterdam \& Philadelphia: John Benjamins Publishing Company.

Clyne, Michael (ed.). 1992. Pluricentric languages: Differing norms in different nations. Berlin: Mouton de Gruyter.

Debrock, Mark. 1977. An acoustic correlate of the force of articulation. Journal of Phonetics 5. 61-80.

Debrock, Mark. 1978. Is the fortis-lenis feature really redundant in Dutch? Leuvense Bijdragen 67. 457-472.

Deumert, Ana \& Wim Vandenbussche (eds.). 2003. Germanic standardizations: Past to present. Amsterdam \& Philadelphia: John Benjamins Publishing Company.

Fikkert, Paula \& Leonie Cornips (eds.). 2003. Linguistics in the Netherlands 2003. Amsterdam \& Philadelphia: John Benjamins Publishing Company.

Geeraerts, Dirk, Stefan Grondelaers \& Dirk Speelman. 1999. Convergentie en divergentie in de Nederlandse woordenschat. Onderzoek naar kleding-en voetbaltermen. Amsterdam: Meertensinstituut.

Geerts, Guido. 1989. In Vlaanderen Vlaams? ['In Flanders Flemish?']. Ons Erfdeel 32. $525-533$.

Gossens, Jan. 1973. De Belgische uitspraak van het Nederlands. De Nieuwe Taalgids (Van Haeringen-nummer). 54-70.

Huls, Erica \& Bert Weltens (eds.). 1999. Artikelen van de Derde Sociolingutstische Conferentie. Delft: Uitgeverij Eburon.

Kissine, Mikhail, Hans Van de Velde \& Roeland van Hout. 2003. The devoicing of fricatives in Standard Dutch. In Paula Fikkert \& Leonie Cornips (eds.), Linguistics in the Netherlands 2003, 93-104. Amsterdam \& Philadelphia: John Benjamins Publishing Company.

Kissine, Mikhail, Hans Van de Velde \& Roeland van Hout. 2005. Acoustic contributions to sociolinguistics: Devoicing of /v/ and /z/ in Dutch. In Maciej Baranowski, Uri Horesh, Keelan Evans \& Giang Nguyen (eds.). Penn Working Papers in Linguistics 10.2. Selected Papers from NWAVE 32, 143-155. Philadelphia: University of Pennsylvania.

Kissine, Mikhail, Hans Van de Velde \& Roeland van Hout. i.p. Regional differences in the acoustic implementation of the $|\mathrm{v} /-\mathrm{If}|$ contrast in Dutch.

Quené, Hugo. 2008. Multilevel modeling of between-speaker and within-speaker variation in spontaneous speech tempo. Journal of the Acoustical Society of America 123 (2). 1104-1113.

Smakman, Dick (2006). Standard Dutch in the Netherlands. A sociolinguistic and phonetic description. Dissertation Radboud Universiteit. Utrecht: Lot.

Van Bezooijen, Renée. 2005. Approximant/r/ in Dutch: Routes and feelings. Speech Communication 47. 15-31.

Van Bezooijen, Renée, René Kager (eds.). 1999. Linguistics in the Netherlands 1999. Amsterdam \& Philadelphia: John Benjamins Publishing Company.

Van Bezooijen, Renée, Suzan Kroezen \& Rob van den Berg. 2002. Front approximant /r/: A new and vigorous change in Dutch. In Hans Broekhuis \& Paula Fikkert (eds.), Linguistics in the Netherlands 2002, 1-12. Amsterdam \& Philadelphia: John Benjamins Publishing Company.

Van de Velde, Hans. 1996a. Variatie en verandering in het gesproken Standaard-Nederlands (1935-1993). Nijmegen: Katholieke Universiteit Nijmegen dissertation.

Van de Velde, Hans. 1996b. A trend study of a trendy change. In Jennifer Arnold, Renée Blake, Brad Davidson, Scott Schwenter \& Julie Solomon (eds.), Sociolinguistic variation: Data, theory and analysis, 501-514. Stanford: CSLI Publications. 
Van de Velde, Hans. 2006. Snoeihard en boterzacht. De $g$ in het Standaardnederlands. Amsterdam. Paper presented at 'Van dialectologie tot variatielinguïstiek', Meertensinsituut Amsterdam. 2 June.

Van de Velde, Hans, Marinel Gerritsen \& Roeland van Hout. 1996. The devoicing of fricatives in Standard Dutch. A real-time study based on radio recordings. Language Variation and Change 8(2). 149-175.

Van de Velde, Hans, Roeland van Hout \& Marinel Gerritsen. 1997. Watching Dutch change: A real time study of variation and change in standard Dutch pronunciation. Journal of Sociolinguistics 1(3). 361-391.

Van de Velde, Hans \& Muriel Houtermans. 1999. Vlamingen en Nederlanders over de uitspraak van nieuwslezers. In Erica Huls \& Bert Weltens (eds.), Artikelen van de Derde Sociolinguïstische Conferentie, 451-462. Delft: Uitgeverij Eburon.

Van de Velde, Hans \& Roeland van Hout. 1999. The pronunciation of (r). In Renée van Bezooijen \& René Kager (eds.). Linguistics in the Netherlands 1999, 177-188. Amsterdam \& Philadelphia: John Benjamins Publishing Company.

Van de Velde, Hans \& Roeland van Hout. 2001. Sprekertypologie voor de slot-n in het Standaard-Nederlands. In Hugo Ryckeboer, Luc Draye \& Jan Stroop (eds.), Taal en Tongval themanummer 14. 89-112.

Van de Velde, Hans \& Roeland van Hout. 2002. Loan words as markers of differentiation. In Hans Broekhuis \& Paula Fikkert (eds.), Linguistics in the Netherlands 2002, 163-173. Amsterdam \& Philadelphia: John Benjamins Publishing Company.

Van de Velde, Hans \& Roeland van Hout. 2003. De deletie van de slot-n. Nederlandse Taalkunde 8(2). 93-114.

Van der Harst, Sander. i.p. The vowel space paradox: A sociophonetic study on Dutch. Dissertation Radboud Universiteit Nijmegen. Utrecht: Lot.

Van der Harst, Sander \& Hans Van de Velde. 2007. 17 g's in het Standaardnederlands? Taal en Tongval 59. 172-195.

Van der Harst, Sander, Hans Van de Velde \& M. E. H. Schouten (2007). Acoustic characteristics of Standard Dutch $/ \mathrm{\gamma} /$. In Proceedings of the $16^{\text {th }}$ International Congress of Phonetic Sciences, Saarbrücken. 1469-1472.

Verhoeven Jo \& Gorik Hageman. 2007. De verstemlozing van fricatieven in Vlaanderen. Nederlandse taalkunde 12(2). 139-152.

Willemyns, Roland. 2003a. Dutch. In Ana Deumert \& Wim Vandenbussche (eds.), Germanic standardizations: Past to present, 93-125. Amsterdam \& Philadelphia: John Benjamins Publishing Company.

Willemyns, Roland. 2003b. Het verhaal van het Vlaams. De geschiedenis van het Nederlands in de zuidelijke Nederlanden. Antwerp: Standaard Uitgeverij.

Hans Van de Velde is lecturer in sociolinguistics at Utrecht University (Utrecht Institute of Linguistics OTS). His work focuses mainly on phonetic variation and change and the patterns of convergence and divergence in the Dutch language area. He recently got involved in research on language variation and change and language standardization in China.

Mikhail Kissine studied linguistics at the Université Libre de Bruxelles (MA and PhD) and the University of Cambridge (MPhil). After having worked in socio-phonetics, he turned his interest to the semantics/pragmatics interface and to autism spectrum disorders. He is currently a post-doctoral fellow of the Fonds de la Recherche Scientifique FNRS at the Université Libre de Bruxelles.

Evie Tops obtained her $\mathrm{PhD}$ at the Vrije Universiteit Brussel, with a socio-phonetic study of $/ r$ / in Flanders. She is now a lecturer in Dutch language and linguistics at the 
Université Libre de Bruxelles. She combined this job for a couple of years with that of project manager at the Dutch Language Union's support center for the teaching of Dutch as a foreign language.

Sander van der Harst studied Linguistics at Utrecht University. In his PhD research he focuses on acoustic variation in the vowel systems of speakers of Standard Dutch and on analysis and normalization problems of vowels in different speech styles. His work is sponsored by both Utrecht University (Utrecht Institute of Linguistics OTS) and Radboud University Nijmegen (Center for Language Studies).

Roeland van Hout is professor of applied and variation linguistics at Radboud University Nijmegen (Center for Language Studies). His work focuses on language variation and change and second language acquisition, from an interdisciplinary perspective (sociology, linguistics, psychology). He also publishes on the application of statistics in language research.

Address for correspondence: Hans Van de Velde, Utrecht Institute of Linguistics OTS, Utrecht University, Trans 10, 3512 JK Utrecht, The Netherlands.

e-mail: h.vandevelde@uu.nl mkissine@ulb.ac.be etops@ulb.ac.be s.vanderharst@uu.nl r.vanhout@let.ru.nl 